\title{
Hybrid NOTES: Complete Endoscopic Resection of the Gastric Wall Assisted by Laparoscopy in a Gastric Fundus Gastrointestinal Stromal Tumor
}

\author{
João Fernandes ${ }^{a, b}$ Diogo Libânio ${ }^{a, c}$ Sílvia Giestas ${ }^{a}$ Tarcísio Araújo ${ }^{a}$ \\ José Ramada ${ }^{a}$ Jorge Canenad Luís Lopes ${ }^{\mathrm{a}}{ }^{\mathrm{e}} \mathrm{e}, \mathrm{f}$ \\ ${ }^{a}$ Gastroenterology Department, Hospital Santa Luzia, Viana do Castelo, Portugal; ${ }^{b}$ Gastroenterology Department, \\ Centro Hospitalar Cova da Beira EPE, Covilhã, Portugal; ' ${ }^{G}$ astroenterology Department, Instituto Português de

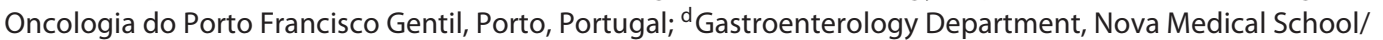 \\ Faculdade de Ciências Médicas de Lisboa, Lisbon, Portugal; ' Life and Health Sciences Research Institute (ICVS), \\ School of Medicine, University of Minho, Braga, Portugal; ${ }^{\mathrm{I}}$ ICVS/3B's - PT Government Associate Laboratory, \\ Braga/Guimarães, Portugal
}

Keywords

Gastrointestinal stromal tumors - Natural orifice endoscopic surgery $\cdot$ Stomach neoplasms

\section{NOTES Híbrido: Ressecção Endoscópica Completa da Parede Gástrica Assistida por Laparoscopia no Tratamento de um Tumor do Estroma Gastrointestinal do Fundo Gástrico}

\section{Palavras Chave}

Tumores do estroma gastrointestinal · Cirurgia endoscópica por orifício natural · Neoplasias gástricas

Laparoscopic wedge resection with a linear stapler is widely accepted in the treatment of gastric gastrointestinal stromal tumors (GISTs) [1,2]. Although not complex [3], this procedure has some major drawbacks, namely failure in identifying the lesion, possible rupture of the capsule with the linear stapler, excessive normal tissue removal, and technical difficulties in reaching areas such as the cardia, fundus, lesser curvature, or peri-pyloric areas [1-5].

\section{KARGER}

E-Mail karger@karger.com www.karger.com/pjg
(C) 2018 Sociedade Portuguesa de Gastrenterologia Published by S. Karger AG, Basel

Karger

Open access

This article is licensed under the Creative Commons Attribution NonCommercial-NoDerivatives 4.0 International License (CC BYNC-ND) (http://www.karger.com/Services/OpenAccessLicense). Usage and distribution for commercial purposes as well as any distribution of modified material requires written permission.
To overcome these limitations, the authors describe a hybrid natural orifice endoscopic surgery (NOTES) technique with endoscopic full thickness resection (EFTR) of the gastric wall assisted by laparoscopy.

We report a 33-year-old female with a $15-\mathrm{mm}$ subepithelial tumor (SET) in the gastric fundus (Fig. 1). Echoendoscopy showed a homogeneous hypoechogenic lesion, depending on the muscularis propria, highly suggestive of a GIST. Given that a follow-up strategy was rejected by the patient, an endoscopic resection assisted by laparoscopy was proposed.

The procedure was initiated by a laparoscopy with clamping of the jejunum to avoid intestinal distension. Endoscopic submucosal dissection (ESD) confirmed that the lesion was in continuity with the muscularis propria (Fig. 2), and a seromuscular incision was performed under laparoscopic control. The lesion was externalized through the oral cavity; the perforation was closed with an endo-GIA 60 (Fig. 3). The procedure (online suppl. video 1; see www.karger.com/doi/10.1159/000491709 for all online suppl. material) lasted $87 \mathrm{~min}$ with no adverse events. Histopathological examination showed a benign GIST, with an R0 resection. The patient had an uneventful recovery with hospital discharge after 5 days. 


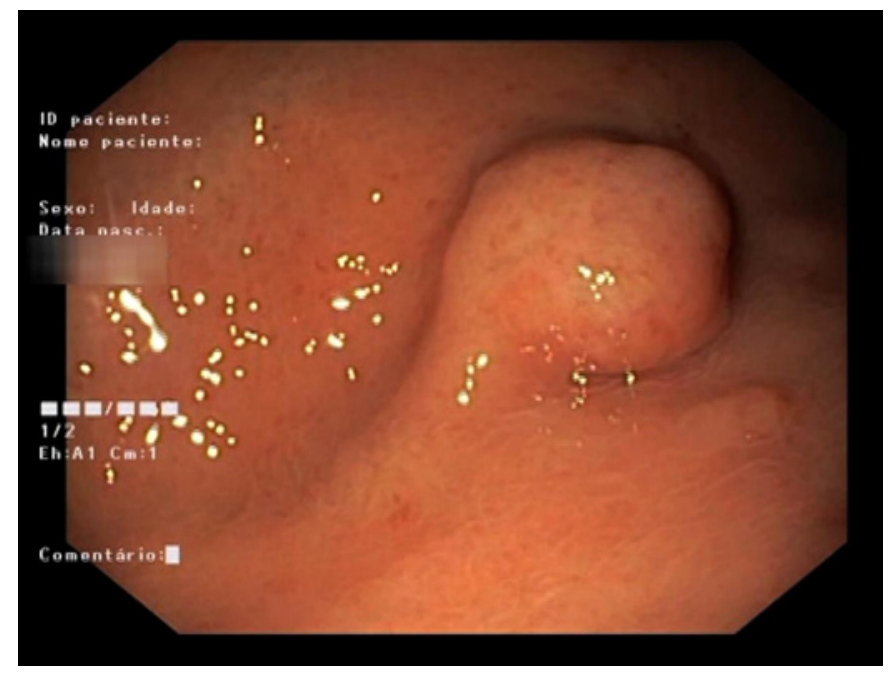

Fig. 1. Fifteen-millimeter SET located in the gastric fundus.

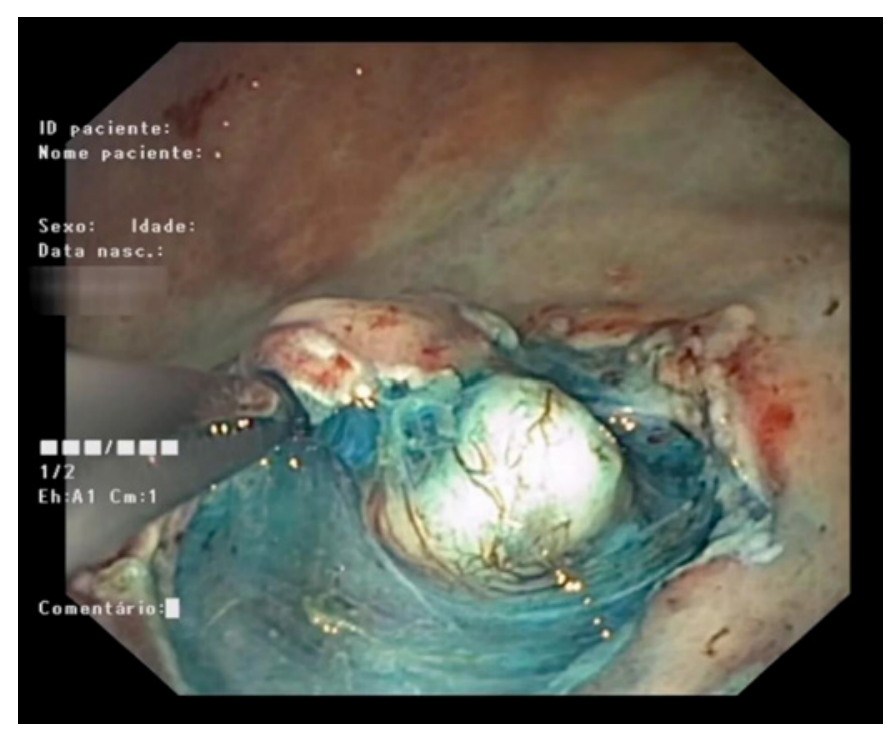

Fig. 2. SET after ESD in continuity with the muscularis propria.

Most gastric SETs have an intraluminal growth pattern and rarely show regional lymph node metastasis; that is the reason why small resections without lymphadenectomy are usually suitable $[1,4,5]$. Since the surgeon is "blind" to these intraluminal lesions, laparoscopic wedge resection may lead to positive margins, to an excessive removal of healthy tissue, or even force conversion to laparotomy to access the lesion.

Since the first report of laparoscopic and endoscopic cooperative surgery (LECS) for the treatment of GISTs by Hiki et al. [6] in 2008, several modified LECS procedures

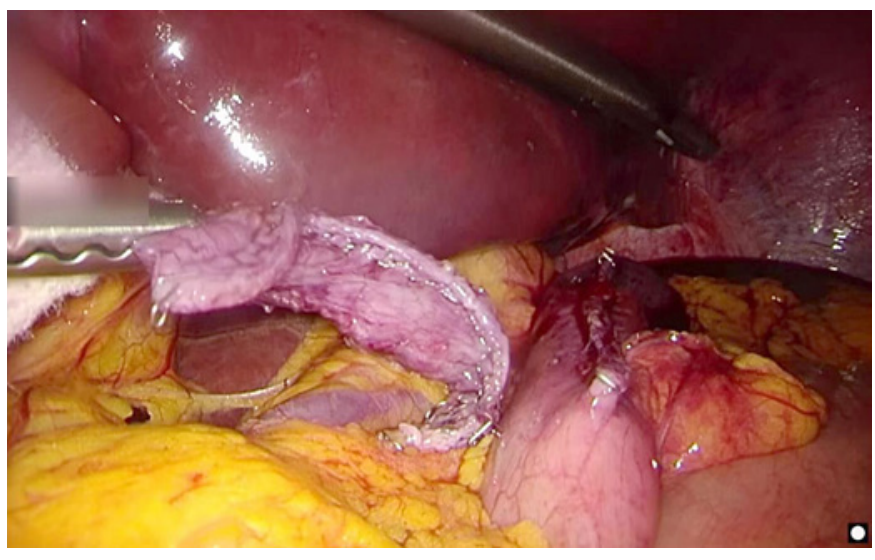

Fig. 3. Laparoscopic view showing the resected healthy tissue after closing the perforation with an endo-GIA 60.

have been described, such as EFTR with laparoscopic assistance, inverted LECS, CLEAN-NET, and NEWS. LECS-related procedures can be divided in exposure and nonexposure techniques, according to the need to open the gastric wall. Exposure techniques such as EFTR with laparoscopic assistance have some theoretical disadvantages (not evidence based) such as the possibility of gastric fluid leakage and potential tumor spillage towards the intraperitoneal space in the case of an ulcerated GIST or when its capsule ruptures [2-5]. On the other hand, nonexposure techniques are technically more demanding and not best suited for lesions that do not protrude to the peritoneal side (as our case), since the seromuscular incision is made by laparoscopy.

Classical LECS, and LECS variants, although routinely performed in the East, are almost unknown in the Western world, where laparoscopic wedge resection remains the cornerstone of treatment. In our opinion, there are several factors that explain this disparity, namely the fact that in the West, these lesions only meet excision criteria with sizes $>20 \mathrm{~mm}$, in contrast to some countries in the East, where these lesions are removed regardless of their size. Furthermore, it is a laborious technique, with the imperative need for multidisciplinary collaboration and proficiency in ESD (an already advanced technique, exclusive of some tertiary centers throughout Europe, with a much wider experience in the East).

To the best of our knowledge, this is the first report of this technique in Portugal, and one of the first in Europe. The hybrid NOTES is feasible in the treatment of gastric GISTs and allows to overcome some of the issues related to surgery. It may be reasonable in the future to see these emerging cooperative techniques applied to lesions rath- 
er than SETs such as early gastric cancers with incomplete resection after ESD, or even deeper layer cancers without metastatic disease in poor candidates for gastrectomy.

\section{Disclosure Statement}

The authors declare no conflicts of interest.

\section{Statement of Ethics}

This study did not require informed consent or review/approval by the appropriate ethics committee.

\section{Author Contributions}

J.F., J.C. and L.L. wrote the manuscript. D.L., S.G., T.A, and J.R. were responsible for the revision of its contents.

\section{References}

Hybrid NOTES in a Gastric Fundus GIST
1 Abe N, Takeuchi H, Yanagida O, Masaki T, Mori T, Sugiyama M, et al: Endoscopic fullthickness resection with laparoscopic assistance as hybrid NOTES for gastric submucosal tumor. Surg Endosc Other Interv Tech 2009;23:1908-1913.

2 Kim HH, Uedo N: Hybrid NOTES: Combined laparo-endoscopic full-thickness resection techniques. Gastrointest Endosc Clin N Am 2016;26:335-373.

3 Kim CG: Endoscopic full-thickness resection combined with laparoscopic surgery. Clin Endosc 2018;51:33-36.
4 Huang J-L, Zheng Z-H, Wei H-B, Chen T-F, Liu J-P, Huang Y, et al: Endoscopy-assisted laparoscopic resections for gastric gastrointestinal stromal tumors: a retrospective study. J Laparoendosc Adv Surg Tech A 2017;27: 110-114.

5 Heo J, Jeon SW: Hybrid natural orifice transluminal endoscopic surgery in gastric subepithelial tumors. World J Gastrointest Endosc 2013;5:428-432.

6 Hiki N, Yamamoto Y, Fukunaga T, Yamaguchi T, Nunobe S, Tokunaga M, et al: Laparoscopic and endoscopic cooperative surgery for gastrointestinal stromal tumor dissection. Surg Endosc Other Interv Tech 2008;22: 1729-1735. 